\title{
Effect of shed geometry on starting mark of woven fabric
}

\author{
Suza Ahmed ${ }^{1}$ (D) Shah Alimuzzaman ${ }^{1}$ - A. K. M. Monjurul Haque ${ }^{2}$
}

Received: 21 August 2019 / Accepted: 2 March 2020 / Published online: 10 March 2020

(c) Springer Nature Switzerland AG 2020

\begin{abstract}
This paper aims to analyze the formation of starting mark on loom and the effect of shed geometry formed by warp yarns under various conditions. The actual cause of starting mark in woven fabric is variable pick spacing and cloth-fell displacement due to the relaxation nature of the warp yarn and fabric and the loom's dynamic characteristics after restarting. Herein, nine woven fabrics of different constructions, compositions are used on an air-jet loom with a series of settings. Three shed angles were selected for specific warp yarn count, and other loom settings like heald frame height, back-rest height and depth, air pressure, take-up correction, automatic start offset, stop position were triggered to change the shed geometry, and then the effect of starting mark on fabric was checked. The pick spacings were then measured from fabric using a projection microscope, whereas various plots were generated utilizing the obtained data to check the pick spacing variation after a certain period of loom stoppage and restarting. Finally, the experimental results were analyzed with standard deviation, coefficient of variation \% analysis using the IBM SPSS statistical program.
\end{abstract}

Keywords Loom $\cdot$ Starting mark $\cdot$ Beat-up force $\cdot$ Shed $\cdot$ Pick spacing $\cdot$ Cloth fell

\section{Introduction}

Starting mark is a functional fault of woven fabric. A starting mark of woven fabric can be defined as an isolated narrow bar running parallel with the inserted weft, starting abruptly and gradually shading away to normal fabric [1]. It may be easily visible to the eye or can be detected by simple test means, depending on the type of yarn used. The viscoelasticity of warp yarns and creep of fabric during a loom stoppage and/or loom dynamic during the loom stop/start-up phases produces starting mark. Such creep shifts the cloth-fell position and causes a variation in pick density during the initial few beat-up cycles when the loom is restarted. Cloth-fell creep also depends on the loom stoppage duration, as well as factors like warp tension and loom stopping position [1]. The variation in pick spacing occurs only for a few picks. Then, the pick spacing returns to its original value. But unfortunately, during loom stoppage or during restarting of loom the cloth fell displaces from its original position due to which the pick spacing of subsequent picks changes and causes starting marks. In running condition, warp is under continuous tension. As there is some elasticity in the thread, so when loom stops warp tries to return to its original relaxed condition. In trying so, it displaces the cloth-fell position due to which starting marks appear in the fabric. The intensity of starting mark has direct influence on physical properties of yarn and fabric, weaving performance, consistency in fabric geometry, strength of the end product, fabric quality, fabric appearance, substantial loss of materials, energy and labor, rejections and costs, productivity and profitability and serviceability [2].

This experimental study deals with the appearance of starting marks on woven fabric which are caused by the specificity of structural and construction parameters like impact of shed geometry, beat-up force and warp tension

$\triangle$ Suza Ahmed, suzaahmed03@gmail.com | 1 Department of Fabric Engineering, Bangladesh University of Textiles, 92, Shaheed Tajuddin Ahmed Avenue, Tejgaon Industrial Area, Dhaka 1208, Bangladesh. ${ }^{2}$ Department of Yarn Manufacturing Engineering, National Institute of Textile Engineering and Research (NITER), Nayarhat, Savar, Dhaka, Bangladesh. 
on starting mark appearance and intensity. Some appropriate loom settings are determined that have unmediated effect on starting mark generation and calibrated later to foreshorten the fault.

\subsection{Literature review}

Starting mark was first investigated and explained by Greenwood and Cowhig [2-4]. They derived some mathematical relationships among the beat-up force, cloth-fell displacement, pick spacing and take-up rate of fabric production [2]. They also summarized that starting mark is caused due to the relaxation of warp yarn and cloth during prolonged loom stoppage [5]. Starting marks mainly take the following forms on fabric. An open mark as shown in Fig. 1a may be produced in the fabric due to insufficient beat-up force during a loom stoppage and restart phase [1]. Conversely, a dense mark may be created (Fig. 1b) due to excessive beatup force or unbalanced weaving conditions.

Several methods have been used to analyze the causes and reductions of the effect of starting marks. Apparently, relaxation of the warp and fabric and loom dynamics during the starting phase is the main cause of starting marks [6]. Cloth-fell creep depends on the duration of stoppage, as well as such factors as the warp tension, loom stopping position, beat-up force, shed geometry, take-up, let-off, reed position and the previous stressing history of the warp [7]. When warp deformation increases, the cloth-fell movement, which can be described as a beat-up duration, increases, too. Theoretically investigating the beat-up process, Nosek has established three main beat-up process parameters as beat-up force, beat-up duration and the impulse of the beatup force [8]. Other authors provided some suggestions to decrease starting mark intensity. They are: (a) controlling shed vertex following a stop signal to prevent faulty pick being beaten-up [9], (b) high-speed start-up by changing the mode of the motor drive for an initial few picks and then back to normality [10,11], (c) shed levelling at stop phase to reduce creep of the warp and fabric [10], (d) reduce tension at stop and restore it before start-up in order to minimize resultant creep of the warp and fabric when the loom is stand still [12], (e) $0^{\circ}$ shed crossings at start-up phase (heald frame crossing without insertion of weft yarns by incorporating slow reverse motion and full speed forward motion of loom [13], (f) starting the loom by applying excessive tension on the warp depending upon the loom starting state

(a)

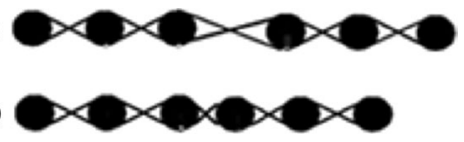

Fig. 1 Types of starting mark a open mark, $\mathbf{b}$ dense mark
[14]. There were also attempts to build a loom with a negative beat-up in order to produce beat-up forces independent of cloth-fell position, the aim being to eliminate the formation of start-up marks because pick spacing would now be independent from cloth-fell position [5]. Vangheluwe and Waesterberg also used Instron models to explain the viscoelastic nature of fell displacement during a loom stoppage due to creep of the warp and fabric [15]. Later, some preventive works were planned. Baldassarre et al. [16] worked on a loom equipped with an online monitoring device that may be stopped when degenerative defects are detected. Thus, by fabric inspection and defect recording, the occurrence of loom stoppage can be reduced. The low-tension method for start-up mark prevention can be implemented on any looms with digital let-off and take-up controls may produce fabrics with untraceable start-up marks after a stoppage [17]. Based on previous works, current work is an attempt to change the factors that causes starting mark.

One of the common factors, identified before, was the warp yarn tension. Warp yarn tension can vary from weaver's beam to heald frame through back-rest roller settings. Due to interlacement warp tension, variations during weaving cause irregularity in weft density and other physical properties of woven fabrics [18]. Hence, average warp tension should remain constant in terms of the weaving cycle or pick sequence [19]. If the tension is higher than the warp yarn can bear, the number of yarn breaks increases and thus, the weaving efficiency decreases. For a satisfactory weaving, the tension levels during weaving can be changed by several mechanical settings like amount of back-rest oscillation, shed crossing and shed stroke [20]. Warp yarns showed higher pull-out forces than weft. The pull-out forces increased with increasing fabric pre-tensions and decreased with increasing pullout speeds [21]. The load-displacement curve contains typical physical phenomena like crimp extension, crimp interchange and fabric deformation behavior [22]. The determined crimp of the straight yarn affected by processinherent tensile forces is $0.1 \%$ at its maximum [23]. Breaking strength of dry fabrics increased when different weave patterns with low crimp percentages were used compared with $1 / 1$ plain fabric [24].

Granitic [25] used a simplified finite element analysis for weaving of a plain fabric process in order to assess the extent of tensile strength degradation in warp yarn. Gu [26] compared the variations in warp tension and determined that the fluctuation decreased as the length of warp at upper shed increased [26]. Glory later used a model based self-optimization (with linear regression models and analyzed $Q-Q$ plots) for weaving to set up the loom for effective shed geometry and reducing warp tension variations [27]. Çelik carried out a mathematical analysis of warp elongation and assumed various motion curves 
with motor-driven positive back-rest system to obtain optimum warp elongation for weaving of different type of fabrics [28]. Genbhardt and Weissenberger found that the warp tension variation of filament warp yarn on air-jet loom during weaving was less than the tension variation of cotton yarn because of the elasticity [29]. Here, the pick spacing for this small increasing will definitely vary. Katunskis [30] developed a theoretical model of beat-up force measurement and investigated the variations in the warp tension and beat-up forces in the weaving loom. He analyzed the difference between the functions $f_{1}$ and $f_{2}$. The experimental beating resistance force $F_{\mathrm{pr}}$ can be obtained by eliminating the vibration of the reed, i.e., the function $f_{2}$. Evaluating the rigidity of the reed, the beating resistance force $F_{\mathrm{pr}}$ can be calculated by the following equation [30]:

$F_{\mathrm{pr}}=F_{1}(\Delta x)-F_{2}(\Delta x)=C_{\text {Reed }}\left[f_{1}(\Delta x)-f_{2}(\Delta x)\right]$

where $C_{\text {Reed }}=$ coefficient of the reed rigidity, $\Delta x=$ displacement of the reed during beat-up.

Some other equations formulated the requirements of the balance of moments around the oscillation point of the back-rest roller. These equations were dependent on the geometry of loom, warp sheet rigidity, warp beam diameter, position of heald frames, back-rest position and the rotation of the warp beam [20]. So, a total loom shed geometry can be considered to present the tension of warp yarns.

A shed geometry is basically formed by minimum two heald frames. One frame moves to the upward direction and other to the downward. A passage of warp yarn between these two frames is created which is called shed. Shed can be of various types. A shed geometry is shown in Fig. 2. Here, $E=$ Fabric at fell of the cloth position before beat-up, $F=$ Fabric at fell of the cloth position after beatup, $a=$ shed angle. Heald frame height makes the shed geometry very important. Depending on the shed angle, the cloth fell as well as pick spacing can be controlled. Again, the back-rest position, beam surface area and free length of warp yarn, all have impact on the shed angle as well as shed geometry.

When shed angle changes, shed geometry changes and it moves the cloth-fell position either backward or forward toward the loom, which has a direct impact on starting mark as well as pick spacing. An asymmetrical shed produces unequal creep in the alternate warp yarns during a loom stoppage. Obtaining the effective beat-up force by reed during weaving is essential to avoid any deviation from ideal pick spacing. Greenwood et al. [2-4] studied that, according to the excess tension theory, there is a certain relation between pick spacing, cloth fell and beat-up force, which is,

$R_{\mathrm{b}}=(L-S) \times\left(\frac{E_{1}}{I_{1}}+\frac{E_{2}}{I_{2}}\right)$

where $R_{\mathrm{b}}=$ beat-up force, $S=$ pick spacing, $L=$ cloth-fell distance, $E_{1}=$ elastic modulus of yarn, $E_{2}=$ elastic modulus of fabric, $I_{1}=$ warp yarn length from beam surface to fell of the cloth, $I_{2}=$ fabric length from fell of the cloth to take-up roller; elastic modulus can be determined by this:

$\mathrm{d} T=\frac{E_{1} \times Z}{l_{1}}$

where $\mathrm{d} T=$ differences between initial tension $(T)$ and warp yarn tension causing extension $\left(T_{1}\right) ; Z=$ yarn extension (equal to pick spacing causing starting mark). Depending on the variable pick spacing, the required additional beatup force can be measured by above equations and can be implemented on the loom (Fig. 3).

Janicijevic [31] proposed a shed limiter device that could limit the shed opening from above and below the

Fig. 2 Shed geometry

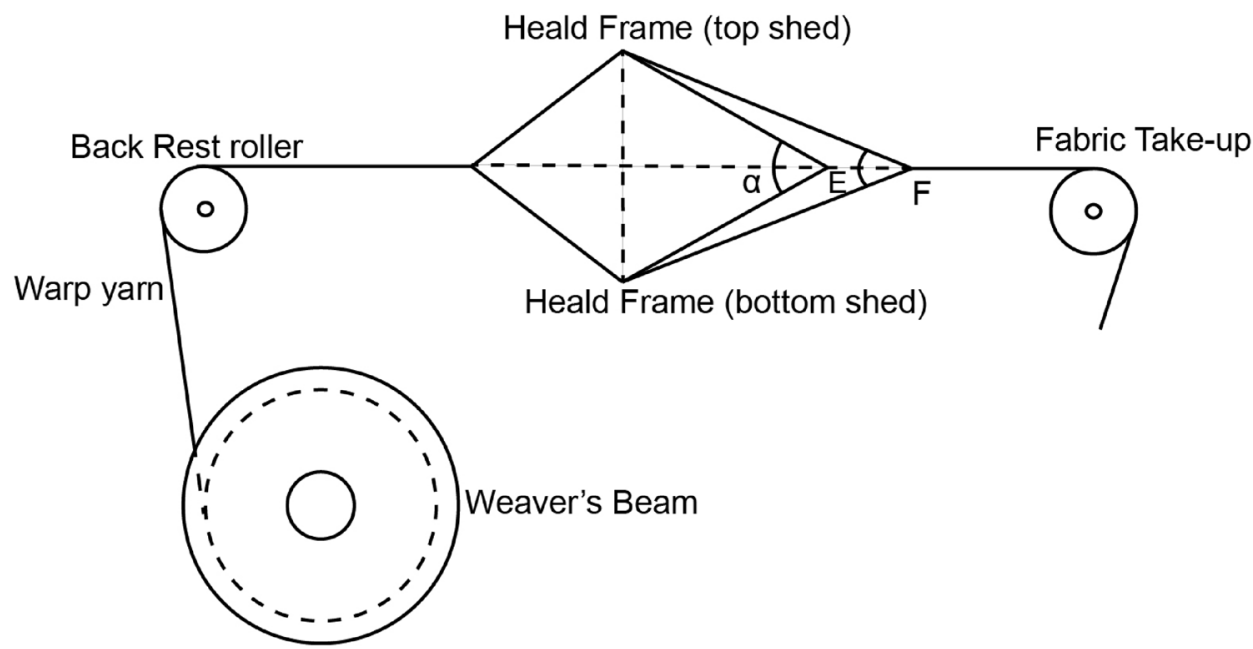


warp and is movable in the warp direction to modulate the shed angle. Katunskis [30] stated that reed is involved with the beat-up mechanism and hence can be used for measuring beat-up force. Catling [32] also identified a reed deformation that should be analogous to that of warp tension.

Starting mark generation can also be initiated due to disturbances in balanced weaving condition. Disturbances in take-up and let-off motion can change the balanced condition according [33]. Figure 4 shows the cross section of Pierce's Model of woven fabric geometry where, $P$ is the take-up length per pick cycle, $I$ is the let-off length of warp per pick cycle, $\Delta /$ is the extension due to warp yarn tension and $\varphi$ is the weaving angle. Chen [33] considers the modular length of the warp yarn in the fabric can be expressed by a straight line and provide following equation for balanced weaving condition:

$P=(I+\Delta l) \cos \varphi$

During a balanced weaving, $P$ and $I$ are constants, and weaving angle and the base warp tension level will remain unaffected. Due to prolonged loom stoppage and the viscoelasticity of yarn and fabric, a slight variation in let-off length $(I$ and $\Delta l)$ will affect the weft density of the fabric. So, we can conclude that when balanced weaving is disturbed by take-up or let-off motion, pick density of fabric will change and influence starting mark generation. One of the main objectives of this research is to find out how shed geometry changes with various loom settings with above equations and affects the intensity of starting mark generation. Again, prolonged loom stop time enhances the starting mark. As coarser yarn possesses more hairiness, it has been observed that by reducing air pressure of main nozzle gives the higher reduction in weft stops per

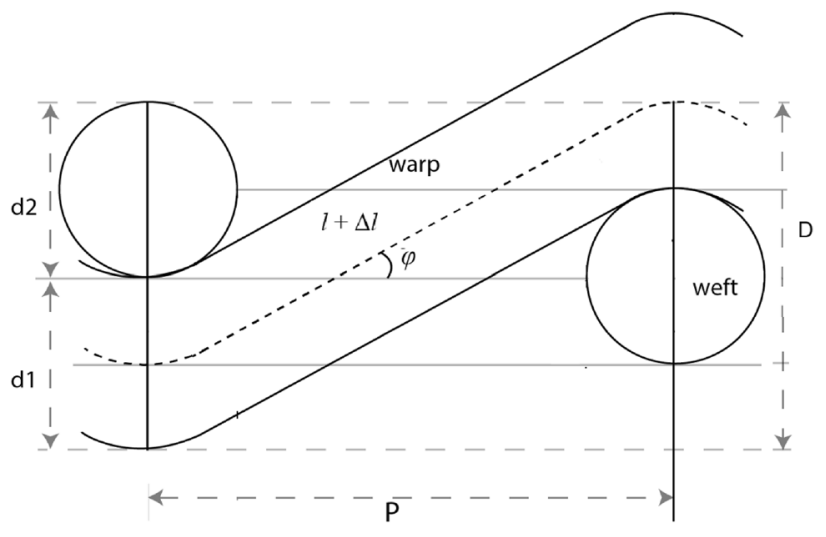

Fig. 4 Pierce's model of woven fabric geometry (balanced condition)

100,000 pick insertion which is followed by synchronizing the air pressure of nozzles. In case of finer yarns, by changing the shed crossing timing gives slight reduction in weft stop value [34]. Therefore, it is worth investigating for the purpose of preventing this type of faults.

\section{Materials and methods}

\subsection{Materials}

Detailed information about the yarn used to produce the required fabric samples with relevant structures is given in Tables 1 and 2.

Detailed information about the fabric samples with relevant structures is given in Tables 3 and 4. Nine samples of same weave structure were used. At different shed angles, samples having same material in weft were developed using same ends/cm and picks/cm. Since pick
Fig. 3 Warp and fabric length during shedding

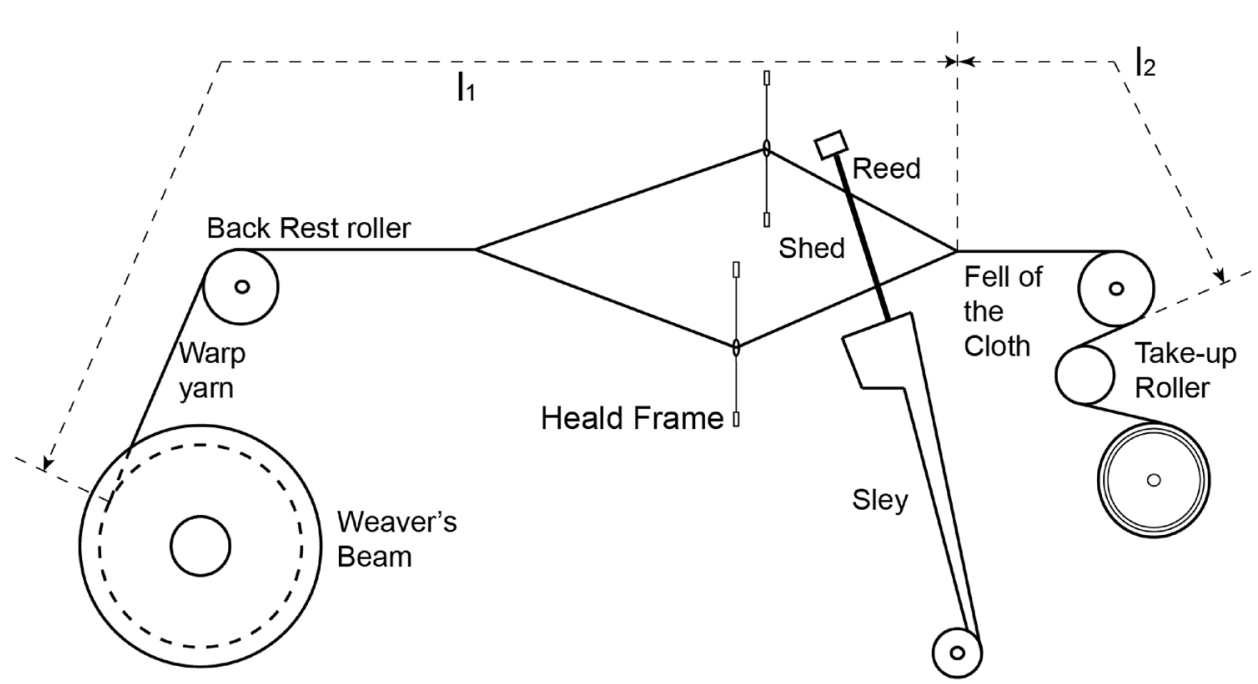


Table 1 Properties of warp yarn used in the experiment

\begin{tabular}{llll}
\hline Yarn properties & Warp count & \\
\hline Yarn count & 50 Tex *OE & 60 Tex OE & 74 Tex OE \\
Yarn type & $100 \%$ Cotton & 100\% Cotton & $100 \%$ Cotton \\
Neps (+200\%)/1000 m m & 33.2 & 24 & 20.7 \\
$\begin{array}{l}\text { Elongation (\%) } \\
\text { Tenacity (cN/tex) }\end{array}$ & 6.8 & 6.9 & 6.3 \\
$\begin{array}{l}\text { Thin places } \\
(-50 \%) / 1000 \mathrm{~m}\end{array}$ & 22 & 13.25 & 12.9 \\
$\begin{array}{l}\text { Thick places } \\
(+50 \%) / 1000 \mathrm{~m}\end{array}$ & 28.5 & 15 & 14 \\
Hairiness (H) & 5.7 & 21.5 & 16.4 \\
\hline
\end{tabular}

${ }^{*} \mathrm{OE}=$ open end rotor yarn

spacing is related with starting mark, different counts for same weft material and picks/cm will show the outcomes more accurately.

\subsection{Experimental methods}

In this experiment, Sample fabrics were woven by a PICANOL loom with mentioned particulars given in Table 4. Six heald frames were used for all sample fabrics with a straight draft, where 4 is used for making body fabric and other 2 is used for making selvedge. Weaving trials were carried out by changing the following parameters depending on fabric construction, and their effects on starting mark intensity were investigated.

a) Jack lever height/shed angle

b) Back-rest height and depth

c) Heald frame height at levelling

d) Air pressure, Automatic Start Offset (ASO), stop position, take-up correction (TUCO)

The machine settings were changed according to an experimental work program. Warp tension, cloth-fell displacements, pick spacings were determined for each machine setting and each sample before and after $2 \mathrm{~min}$
Table 3 Fabrics used in the experiment

\begin{tabular}{llll}
\hline Sample code & Warp count $\times$ Weft count & EPCM $\times$ PPCM & Weave \\
\hline SMP-01 & 50 Tex OE $\times 34$ Tex & $26 \times 20$ & $3 / 1{ }^{*}$ RHT \\
SMP-02 & 60 Tex OE $\times$ 52 Tex & $28 \times 22$ & $3 / 1 \mathrm{RHT}$ \\
SMP-03 & 74 Tex OE $\times$ 50 Tex OE & $26 \times 23$ & $3 / 1 \mathrm{RHT}$ \\
SMP-04 & 50 Tex OE $\times$ 50 Tex & $26 \times 20$ & $3 / 1 \mathrm{RHT}$ \\
SMP-05 & 60 Tex OE $\times$ 40 Tex & $28 \times 22$ & $3 / 1 \mathrm{RHT}$ \\
SMP-06 & 74 Tex OE $\times$ 37 Tex OE & $26 \times 23$ & $3 / 1 \mathrm{RHT}$ \\
SMP-07 & 50 Tex OE $\times$ 67 Tex & $26 \times 20$ & $3 / 1 \mathrm{RHT}$ \\
SMP-08 & 60 Tex OE $\times 32$ Tex & $28 \times 22$ & $3 / 1 \mathrm{RHT}$ \\
SMP-09 & 74 Tex OE $\times 30$ Tex OE & $26 \times 23$ & $3 / 1 \mathrm{RHT}$ \\
\hline
\end{tabular}

${ }^{*} \mathrm{RHT}=$ right hand twill, EPCM = ends per $\mathrm{cm}, \mathrm{PPCM}=$ picks per $\mathrm{cm}$

loom stoppage. Machine settings will be given in the results and discussion part.

\subsubsection{Measurement of fabric properties}

Performance of fabric samples was evaluated in terms of breaking and elongation strength, areal density (gram/ square meter), thickness, abrasion resistance, tear resistance and air permeability. An Instron Series 2701 tester, based on ASTM D5034, was used to determine the strength of all samples. The abrasion resistances of the fabrics were tested according to ASTM D 4966-98. Abrasion resistance of the samples was measured with the help of a Martindale Abrasion Tester. The abrasion resistance was determined by the mass loss $\%$ as the difference between the masses before and after abrasion cycles of 5000, 7500 and 10,000. The Shirley thickness tester (SDL 94) and a GSM Cutter (James H. Heal), based on ASTM D1777 and ASTM D3776, were used to determine the thickness and areal density of the samples. Shirley air permeability tester (SDL) was used to determine the air permeability based on ASTM D737-04. The Elmendorf tear tester, based on D2261ASTM, was used to determine the tear resistance of the samples. All the experiments were performed under standard conditions $\left(65 \pm 2 \% \mathrm{RH}\right.$ and $\left.20 \pm 2{ }^{\circ} \mathrm{C}\right)$.
Table 2 Properties of weft yarn used in the experiment

\begin{tabular}{lllllllllll}
\hline Yarn properties & \multicolumn{3}{l}{ Polyester } & \multicolumn{3}{l}{ 100\% Cotton, OE } \\
\hline Yarn count & 34 Tex & 50 Tex & 67 Tex & 30 Tex & 37 Tex & 50 Tex & 32 Tex & 40 Tex & 52 Tex \\
Elongation (\%) & 12 & 13.5 & 17 & 6.7 & 6.2 & 6.1 & 27.5 & 36.2 & 38.5 \\
Tenacity (cN/tex) & 41.5 & 43.8 & 48.55 & 15.9 & 16.9 & 18.1 & 18.5 & 19.9 & 20.5 \\
Thin places (-50\%)/1000 m & - & - & - & 85 & 54 & 30 & - & - & - \\
Thick places (+50\%)/1000 m & - & - & - & 36 & 27 & 28 & - & - & - \\
Hairiness (H) & - & - & - & 4.2 & 4.8 & 5.6 & - & - & - \\
Neps (+200\%)/1000 m & - & - & - & 42.5 & 38 & 32 & - & - & - \\
\hline
\end{tabular}


Table 4 Particulars of weaving machine

\begin{tabular}{|c|c|c|c|c|c|c|c|c|}
\hline Loom & Model & Shedding type & Take-up type & Let-off type & Avg. RPM & Total ends & Reed width & Shed crossing \\
\hline $\begin{array}{l}\text { PICANOL air-jet } \\
\text { loom }\end{array}$ & $\begin{array}{l}\text { OMNIplus sum- } \\
\text { mum }\end{array}$ & $\begin{array}{c}\text { Staubli cam } \\
\text { shedding }\end{array}$ & $\begin{array}{l}\text { Electronic take- } \\
\text { up }\end{array}$ & $\begin{array}{c}\text { Electronic } \\
\text { let-off }\end{array}$ & 900 & 4464 & $66^{\prime \prime}$ & $299^{\circ}$ \\
\hline
\end{tabular}

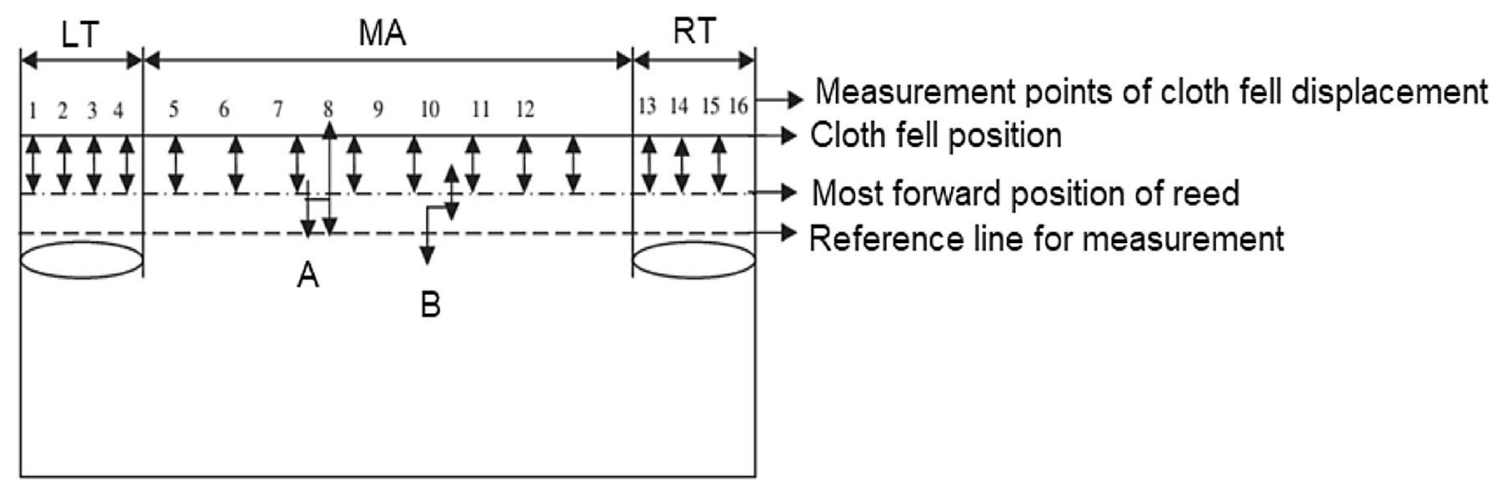

Fig. 5 CFD measurement ( $L T$ : left temple region; $R T$ : right temple region; $M A$ : cloth-fell distance measurement region in the middle of the fabric)

\subsubsection{Measurement of the cloth-fell distance (CFD) [35]}

Cloth-fell distance was measured for all settings and samples. Cloth-fell distance was measured from right and left temple side and between the temples. Ten measurements were taken between the temples, and five measurements were taken from each temple side. Measurement and reference points are shown in Fig. 5. Cloth-fell distance $=(A$ $-B$ ); where, $A=$ distance between cloth-fell position and reference line; $B=$ distance between the most forward position of reed and the reference line.

\subsubsection{Measurement of warp tension}

A WIRA warp yarn tension meter was used to measure warp yarn tension in $\mathrm{cN}$ for single yarn on warp sheet between the free length from back-rest roller to drop wire. In this way, 12 warp tension value was recorded for every individual setting of back-rest height and depth and saved to a SPSS file.

\subsubsection{Measurement of Pick Spacing}

A projection microscope (AARSON, RSB-17) was used to measure the pick spacings for 9 samples prepared under various loom parameters against three shed angles, $26^{\circ}$, $28^{\circ}$ and $30^{\circ}$ [5]. Six pick spacings before and after every loom stoppage were measured. The reference and average pick spacings were noted from the actual picks per centimeter (ppcm) for comparison with the values obtained.
The first pick spacing produced just after restarting the machine was called pick sequence 0 .

\subsubsection{Adjustment of jack lever, back rest and heald frame}

As shed angle is related with jack lever height, it was selected as per Picanol loom manual. Three shed angles were selected $\left(26^{\circ}, 28^{\circ}\right.$ and $\left.30^{\circ}\right)$ for every construction of fabric, and jack lever heights were also adjusted accordingly. Here, for $3 / 1$ right hand twill fabric, back-rest heights used were $8,10,12$ and 14. Heald frame heights were (98, 100 and $102 \mathrm{~mm}$ ) also adjusted in levelling condition.

\section{Results and discussions}

\subsection{Fabric properties}

The properties of fabric samples and test results are illustrated in Table 5, respectively.

According to the results (Table 5), below shed angle of $28^{\circ}$, fabric shows good behavior in terms of all mentioned properties for polyester weft yarn samples. Above $28^{\circ}$, the breaking force, tear resistance and breaking elongation start to fall. Below shed angle of $30^{\circ}$, fabric shows good behavior in terms of all mentioned properties for cotton weft yarn samples. At same shed angle, tear resistance values for cotton fabric samples are lower comparing with polyester and core-spun samples. At higher shed angles, mass loss $\%$ for $100 \%$ cotton yarn is higher than other samples. Abrasion resistance of polyester sample is less 
Table 5 Fabric properties at different shed angles

\begin{tabular}{|c|c|c|c|c|c|c|c|c|c|c|c|c|c|}
\hline \multirow[t]{2}{*}{ Sample Code } & \multirow[t]{2}{*}{ Shed angle } & \multicolumn{2}{|c|}{$\begin{array}{l}\text { Breaking Force } \\
\text { (N) }\end{array}$} & \multicolumn{2}{|c|}{$\begin{array}{l}\text { Breaking } \\
\text { Elongation } \\
(\%)\end{array}$} & \multirow[t]{2}{*}{$\begin{array}{l}\text { Fabric } \\
\text { thickness } \\
(\mathrm{mm})\end{array}$} & \multicolumn{2}{|c|}{$\begin{array}{l}\text { Tear Resist- } \\
\text { ance }(\mathrm{N})\end{array}$} & \multirow[t]{2}{*}{$\begin{array}{l}\text { Air perme- } \\
\text { ability } \mathrm{ml} / \\
\left(\mathrm{s} \mathrm{cm}^{2}\right)\end{array}$} & \multirow[t]{2}{*}{$\begin{array}{l}\text { Areal den- } \\
\text { sity }(\mathrm{gm} / \\
\left.\mathrm{m}^{2}\right)\end{array}$} & \multicolumn{3}{|c|}{$\begin{array}{l}\text { Abrasion resistance } \\
\text { (mass loss \% after dif- } \\
\text { ferent cycles) }\end{array}$} \\
\hline & & Warp & Weft & Warp & Weft & & Warp & Weft & & & 5000 & 7500 & 10,000 \\
\hline \multirow[t]{3}{*}{ SMP-01 } & $26^{\circ}$ & 1008.9 & 600.1 & 18.7 & 16.4 & 0.60 & 47.9 & 37.2 & 140 & 245 & 2.7 & 3.2 & 2.4 \\
\hline & $28^{\circ}$ & 1052.3 & 627.3 & 18.3 & 17.8 & 0.61 & 46.8 & 36.5 & 150 & 248 & 2.2 & 3.0 & 3.5 \\
\hline & $30^{\circ}$ & 1005.5 & 615.7 & 15.5 & 13.2 & 0.61 & 44.8 & 37.5 & 136 & 254 & 2.5 & 3.5 & 3.2 \\
\hline \multirow[t]{3}{*}{ SMP-02 } & $26^{\circ}$ & 1355.5 & 802.5 & 23.9 & 27.3 & 0.69 & 55.5 & 45.5 & 195 & 317 & 1.9 & 2.9 & 3.2 \\
\hline & $28^{\circ}$ & 1402.2 & 830.5 & 24.1 & 28.5 & 0.73 & 58.6 & 48.9 & 189 & 331 & 1.9 & 2.2 & 2.5 \\
\hline & $30^{\circ}$ & 1299.2 & 755.5 & 23.5 & 28.2 & 0.68 & 57.9 & 45.1 & 180 & 307 & 1.8 & 2.7 & 4.4 \\
\hline \multirow[t]{3}{*}{ SMP-03 } & $26^{\circ}$ & 1487.5 & 827.5 & 30.7 & 41.6 & 0.76 & 33.1 & 38.6 & 200 & 360 & 2.4 & 3.2 & 3.0 \\
\hline & $28^{\circ}$ & 1521.7 & 897.3 & 31.4 & 42.9 & 0.78 & 34.9 & 37.7 & 220 & 364 & 1.9 & 2.8 & 3.1 \\
\hline & $30^{\circ}$ & 1589.8 & 954.1 & 34.6 & 43.2 & 0.79 & 37.8 & 40.1 & 190 & 373 & 4.5 & 4.9 & 5.7 \\
\hline \multirow[t]{3}{*}{ SMP-04 } & $26^{\circ}$ & 1069.4 & 620.1 & 16.1 & 14.9 & 0.61 & 46.6 & 36.4 & 160 & 264 & 2.5 & 2.2 & 3.8 \\
\hline & $28^{\circ}$ & 1112.3 & 686.3 & 15.3 & 15.5 & 0.64 & 47.1 & 35.6 & 176 & 270 & 1.8 & 3.5 & 4.5 \\
\hline & $30^{\circ}$ & 1179.9 & 925.3 & 15.2 & 14.2 & 0.64 & 47.3 & 38.4 & 166 & 272 & 2.6 & 3.0 & 3.1 \\
\hline \multirow[t]{3}{*}{ SMP-05 } & $26^{\circ}$ & 1268.3 & 720.1 & 23.9 & 25.3 & 0.65 & 51.5 & 44.5 & 165 & 290 & 2.4 & 3.5 & 4.5 \\
\hline & $28^{\circ}$ & 1300.5 & 725.1 & 24.1 & 28.1 & 0.66 & 52.3 & 47.1 & 169 & 299 & 2.5 & 2.6 & 3.0 \\
\hline & $30^{\circ}$ & 1255.1 & 765.5 & 22.8 & 27.8 & 0.68 & 54.7 & 47.5 & 160 & 302 & 2.5 & 4.0 & 4.7 \\
\hline \multirow[t]{3}{*}{ SMP-06 } & $26^{\circ}$ & 1381.5 & 800.4 & 26.9 & 33.8 & 0.67 & 30.5 & 32.4 & 196 & 311 & 2.1 & 3.5 & 3.5 \\
\hline & $28^{\circ}$ & 1420.6 & 772.5 & 26.4 & 37.6 & 0.71 & 32.9 & 35.2 & 216 & 324 & 1.6 & 2.5 & 3.0 \\
\hline & $30^{\circ}$ & 1484.8 & 855.2 & 27.5 & 36.1 & 0.73 & 32.8 & 36.7 & 199 & 330 & 3.1 & 3.9 & 4.2 \\
\hline \multirow[t]{3}{*}{ SMP-07 } & $26^{\circ}$ & 1369.2 & 829.5 & 26.1 & 24.2 & 0.68 & 48.9 & 45.2 & 200 & 312 & 2.0 & 2.9 & 3.0 \\
\hline & $28^{\circ}$ & 1412.4 & 886.3 & 27.5 & 27.2 & 0.70 & 49.6 & 46.3 & 186 & 319 & 2.0 & 3.2 & 3.6 \\
\hline & $30^{\circ}$ & 1369.6 & 898.5 & 24.1 & 21.5 & 0.70 & 47.4 & 44.3 & 190 & 322 & 2.1 & 3.4 & 4.2 \\
\hline \multirow[t]{3}{*}{ SMP-08 } & $26^{\circ}$ & 1092.5 & 650.2 & 20.7 & 21.5 & 0.60 & 50.0 & 42.5 & 158 & 264 & 2.1 & 3.5 & 3.6 \\
\hline & $28^{\circ}$ & 1153.4 & 688.3 & 22.8 & 21.9 & 0.64 & 50.5 & 40.9 & 176 & 278 & 2.2 & 2.4 & 3.8 \\
\hline & $30^{\circ}$ & 1295.2 & 735.1 & 21.3 & 20.8 & 0.66 & 52.1 & 41.8 & 170 & 281 & 1.7 & 3.7 & 4.1 \\
\hline \multirow[t]{3}{*}{ SMP-09 } & $26^{\circ}$ & 1314.7 & 750.1 & 31.1 & 32.6 & 0.64 & 29.9 & 31.8 & 190 & 302 & 2.2 & 2.1 & 3.2 \\
\hline & $28^{\circ}$ & 1380.5 & 762.8 & 29.4 & 34.5 & 0.68 & 33.5 & 34.7 & 180 & 305 & 2.1 & 2.6 & 3.5 \\
\hline & $30^{\circ}$ & 1381.9 & 795.2 & 29.7 & 33.4 & 0.69 & 34.6 & 34.5 & 175 & 314 & 2.5 & 3.9 & 4.7 \\
\hline
\end{tabular}

affected by shed angle changing. The areal density values start to increase with an increase in shed angle for all samples.

\subsection{Effect of the shed angle and heald frame height on starting mark}

Since high shed angle and high frame height move the cloth fell away from the fabric, hence the pick spacing increases and it causes a clearly visible open mark on the fabric [36].

According to the results (Table 6), for polyester weft yarn samples, with shed angle of $30^{\circ}$, an increase in heald frame height $100 \mathrm{~mm}$ will increase the starting mark visibility. But, with $102 \mathrm{~mm}$ height, the visibility will be much lower. For, core-spun weft yarn samples, with shed angle of $26^{\circ}$, an increase in heald frame will tend to dense mark with low pick spacing. But, for cotton yarn, higher the frame height, very much higher the mark visibility. Again, less stoppage time will reduce the visibility of starting mark [17]. Here, the coefficient of variation (CV \%) obtained with core-spun at $26^{\circ}$ shed angle is much higher. Experimental results are used to plot 3 graphs for pick spacing (Fig. 6), where the rise of the pick spacings from the ref. pick spacings at pick sequence 0 will lead to a possible starting mark for various heald frame heights at specific shed angles.

\subsection{Effect of back-rest height and depth on starting mark}

According to the results (Table 7), for both cotton warp and weft yarn samples, with shed angle of $28^{\circ}$, an increase in back-rest roller height from 8 to $12 \mathrm{~cm}$ and depth from 2 to $3 \mathrm{~cm}$ will decrease the starting mark visibility as well as the pick spacing from ref. pick spacing 
Table 6 Starting mark observation for shed angle with different heald frame height at levelling

\begin{tabular}{|c|c|c|c|c|c|c|c|c|c|}
\hline Shed angle & Sample & $\begin{array}{l}\text { Heald frame } \\
\text { height at level- } \\
\text { ling, } \mathrm{mm}\end{array}$ & $\mathrm{ppcm}$ & $\begin{array}{l}\text { Loom stoppage } \\
\text { time }\end{array}$ & $\begin{array}{l}\text { Ref. pick } \\
\text { spacing, } \\
\mu \mathrm{m}\end{array}$ & $\begin{array}{l}\text { First Pick spacing } \\
\text { after loom restart- } \\
\text { ing, } \mu \mathrm{m}\end{array}$ & $\begin{array}{l}\text { Avg. pick } \\
\text { spacing, } \\
\mu \mathrm{m}\end{array}$ & SD & $\begin{array}{l}\text { Coefficient } \\
\text { of variation } \\
\text { (CV \%) }\end{array}$ \\
\hline \multirow[t]{3}{*}{$30^{\circ}$} & SMP-01 & 98 & 20 & $3 \min$ & 488.5 & 564 & 505.5 & & \\
\hline & & 100 & & $3 \min$ & & 579 & 510 & 5.24 & 1.04 \\
\hline & & 102 & & $3 \min$ & & 545 & 499.5 & & \\
\hline \multirow[t]{3}{*}{$26^{\circ}$} & SMP-02 & 98 & 22 & $3 \min$ & 461.8 & 408 & 453.9 & & \\
\hline & & 100 & & $2 \min$ & & 508 & 470.2 & 8.16 & 1.77 \\
\hline & & 102 & & $1 \min 45 \mathrm{~s}$ & & 437 & 460.6 & & \\
\hline \multirow[t]{3}{*}{$28^{\circ}$} & SMP-03 & 98 & 23 & $3 \mathrm{~min}$ & 437.9 & 391 & 433.4 & & \\
\hline & & 100 & & $2 \min$ & & 469 & 438.8 & 4.07 & 0.93 \\
\hline & & 102 & & $1 \min 45 \mathrm{~s}$ & & 481 & 441.4 & & \\
\hline
\end{tabular}

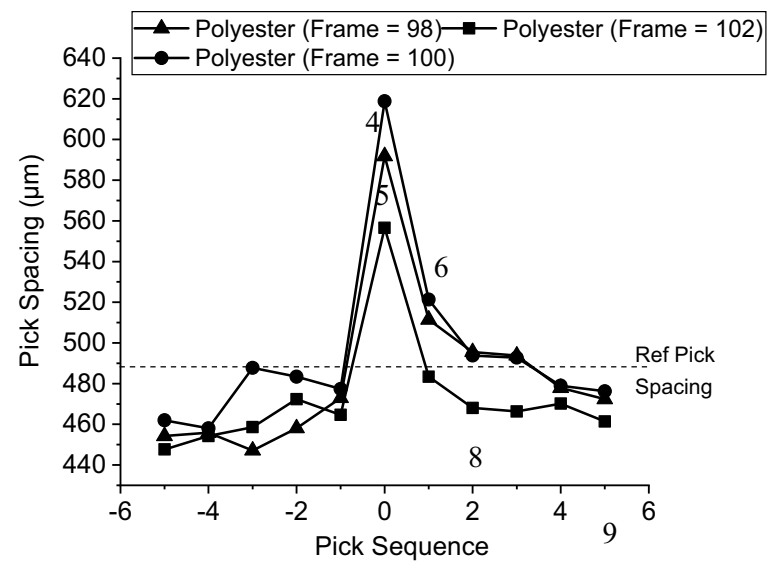

(a)

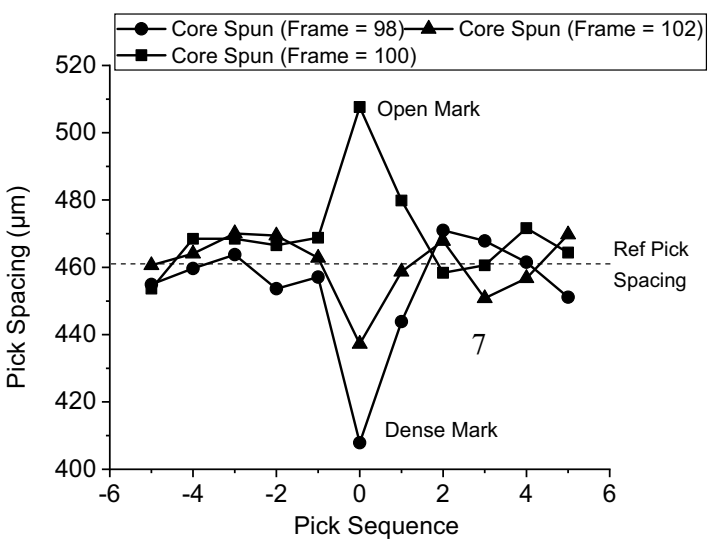

(b)

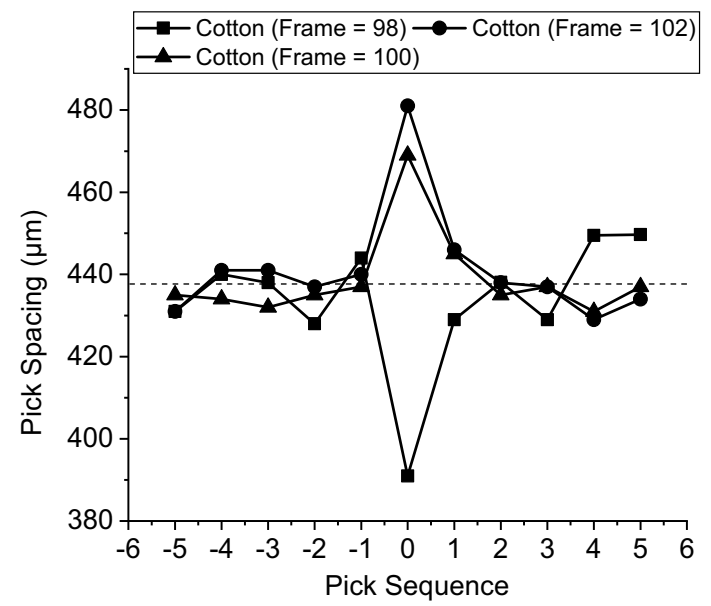

(c)

Fig. 6 Pick spacing $(\mu \mathrm{m})$ for different held frame height against specific shed angle. a Polyester weft yarn at $30^{\circ}$; b core-spun weft yarn at $26^{\circ}$; c cotton weft yarn at $30^{\circ}$ 
Table 7 Starting mark observation for shed angle at different back-rest height and depth

\begin{tabular}{|c|c|c|c|c|c|c|c|c|c|}
\hline Warp \& weft count & Shed angle & $\begin{array}{l}\text { Back-rest } \\
\text { height, } \mathrm{cm}\end{array}$ & $\begin{array}{l}\text { Back-rest } \\
\text { depth, cm }\end{array}$ & $\begin{array}{l}\text { Yarn tension } \\
\text { (before), } \mathrm{cN}\end{array}$ & $\begin{array}{l}\text { Yarn tension } \\
\text { (after), cN }\end{array}$ & $\begin{array}{l}\text { First Pick spacing } \\
\text { after restarting, } \mu \mathrm{m}\end{array}$ & $\begin{array}{l}\text { Avg. pick } \\
\text { spacing, } \\
\mu \mathrm{m}\end{array}$ & SD & CV \% \\
\hline \multirow[t]{4}{*}{$74 \mathrm{Tex} \mathrm{OE} \times 50 \mathrm{Tex} \mathrm{OE}$} & $28^{\circ}$ & 14.0 & 3.0 & 75.0 & 151.8 & 486 & 442.2 & & \\
\hline & & 12.0 & 3.0 & 75.0 & 134.3 & 467 & 439.8 & 3.5 & 0.8 \\
\hline & & 10.0 & 2.0 & 75.0 & 104.4 & 479 & 446.0 & & \\
\hline & & 8.0 & 2.0 & 75.0 & 75.0 & 529 & 447.4 & & \\
\hline \multirow[t]{4}{*}{60 Tex OE $\times 52$ Tex } & $26^{\circ}$ & 14.0 & 3.0 & 65.0 & 127.5 & 410 & 448.2 & & \\
\hline & & 12.0 & 3.0 & 65.0 & 114.2 & 482 & 456.0 & 6.2 & 1.4 \\
\hline & & 10.0 & 2.0 & 65.0 & 88.5 & 488 & 458.9 & & \\
\hline & & 8.0 & 2.0 & 65.0 & 65.0 & 500 & 462.9 & & \\
\hline \multirow[t]{4}{*}{50 Tex OE $\times 34$ Tex } & $30^{\circ}$ & 14.0 & 3.0 & 55.0 & 168.4 & 525 & 497.7 & & \\
\hline & & 12.0 & 3.0 & 55.0 & 129.1 & 560 & 502.8 & 3.6 & 0.7 \\
\hline & & 10.0 & 2.0 & 55.0 & 109.5 & 560 & 505.9 & & \\
\hline & & 8.0 & 2.0 & 55.0 & 55.0 & 577 & 504.8 & & \\
\hline
\end{tabular}

$437 \mu \mathrm{m}$, but with $14 \mathrm{~cm}$ height an open mark re-appears as pick spacing increases. Loom stopping time was $2 \mathrm{~min}$ (Fig. 7).

Sheikhzadeh et al. [19] explained the reason behind changing in warp tension due to back-rest height and depth is related the angle created by back rest with warp yarn from beam by an equation and can be explained with Fig. 8. Where, $F=$ load on warp yarn applied by back-rest roller, $T=$ warp yarn tension, $R_{1}=$ resultant warp tension, $\theta=$ angle of force applied on back-rest roller on warp, $\beta=$ angle between warp from beam and $x$-axis of back rest, Considering the figure, following equations can be derived: $F=R_{1} \cos (\varphi-\theta)$ and $R_{1}=2 T \cos \varphi$. Combining these two equations, following relation was obtained:

$\frac{F}{T}=\cos \theta(1-\cos \beta)+\sin \theta \Delta \sin \beta$

Assuming $F / T$ ratio is constant, the warp yarn tension will not vary by if warp beam diameter is decreased [19]. $\mathrm{F} / \mathrm{T}$ ratio is dependent on $\theta$ and $\beta$ angles; hence, this will have an impact on the shed angle as well as the pick spacing variations. From Table 3, it can be seen that changing back-rest height and depth will surely change its position and ( $\theta$ and $\beta$ angles) it will change yarn tension during weaving and also during loom stationary period. The amount of $\theta$ depends on the design of the back-rest roller, and the $\beta$ depends on warp beam diameter. The reduction in beam diameter will cause specific change in $\beta ;$; thus, $F / T$ ratio will also change when loom will stop. A graphical representation (Fig. 9) of $F / T$ ratio changing against specific contact angle under various conditions of $\theta\left(45^{\circ}, 60^{\circ}, 90^{\circ}\right.$, $120^{\circ}$ ) may express the context.

\subsection{Effect of warp tension on pick spacing (starting mark) and required beat-up force}

After making some changes on back-rest height, depth, some tension will be imparted on yarn which will cause some significant amount extension on warp yarn. As a result, due to a $2 \mathrm{~min}$ loom stoppage for every sample, the cloth-fell distance will deviate from the actual one. Table 8 shows the experimental results obtained for length extension and the beat-up forces required for all 9 samples due to warp tension increasing to avoid the variation in pick spacing from the last pick as well as reference pick spacing. In order to determine the effect of beat-up force $\left(R_{\mathrm{b}^{\prime}}\right.$ Newton) on pick spacing and warp yarn tension in relation with cloth-fell distance, Eq. (2) and (3) were used [36].

According to the results, with an increase in warp tension, starting mark visibility may increase if accurate beatup force could not be applied; hence, pick spacing will vary from actual [37].

Experimental results are used to plot a graph for changes warp yarn tension and the required beat-up force to avoid starting mark and make the pick spacing closer to reference pick spacing (Fig. 10). For low required beatup force, the visibility of starting mark will become lower.

\subsection{Weft yarn count and picks per centimeter (ppcm)}

The changes in picks per centimeter (ppcm) and weft count will change the cover factor and crimp \% which have considerable effect on the weaving performance as well as fabric strength [38]. As count and fiber composition used both in warp and weft may enhance the woven fabric properties, changes in these parameters may be reflected 


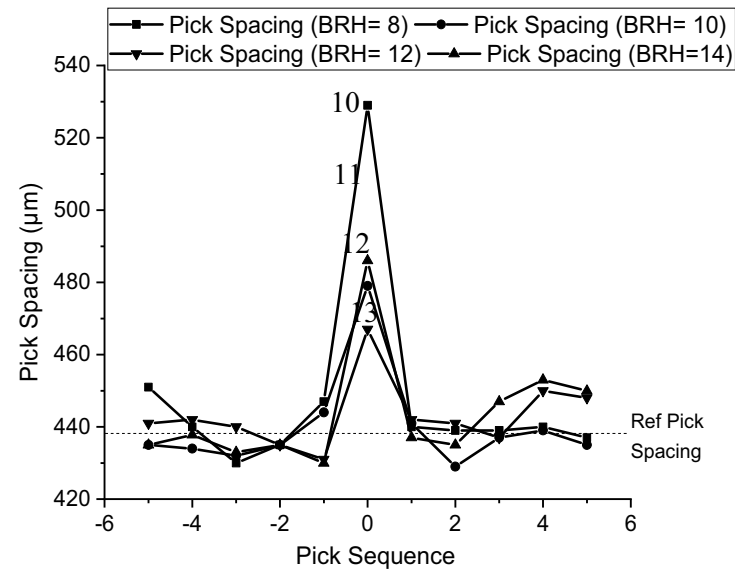

(a)

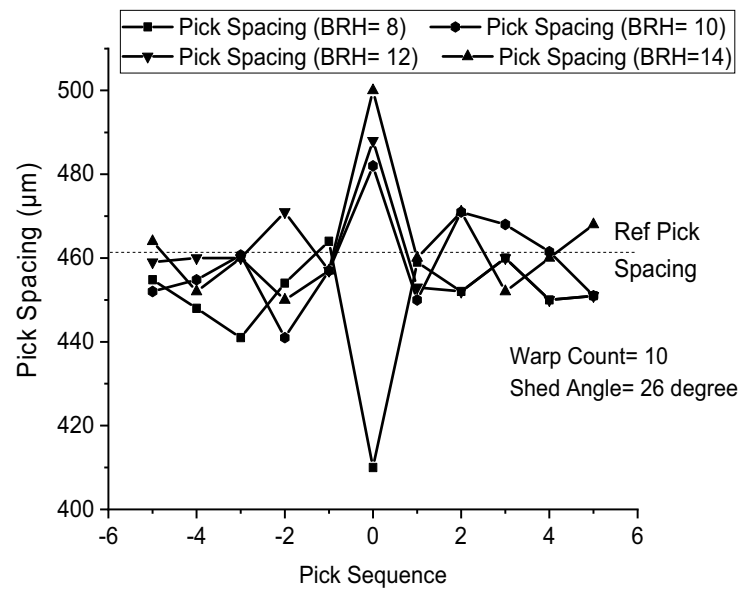

(b)

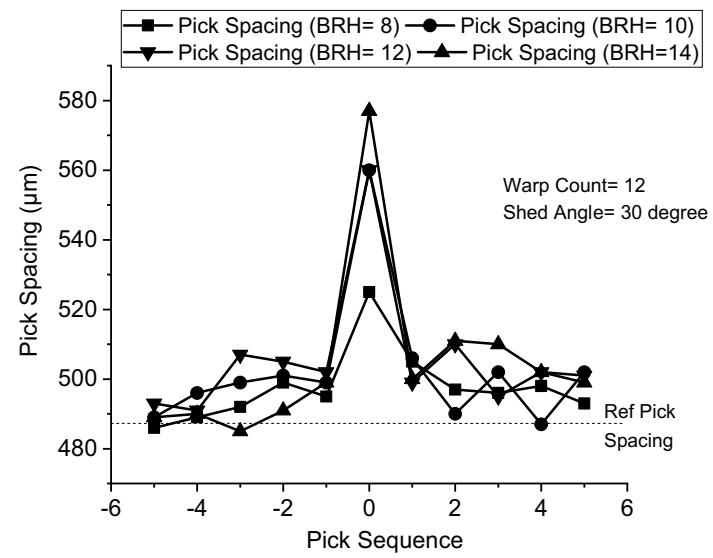

(c)

Fig. 7 Pick spacing $(\mu \mathrm{m})$ for different back-rest height against specific shed angle. a Cotton weft at $28^{\circ} ; \mathbf{b}$ core-spun weft at $26^{\circ} ; \mathbf{c}$ polyester weft at $30^{\circ}$

in the starting mark [5]. All samples and the obtained avg. pick spacings of these samples were investigated and listed in Table 9.

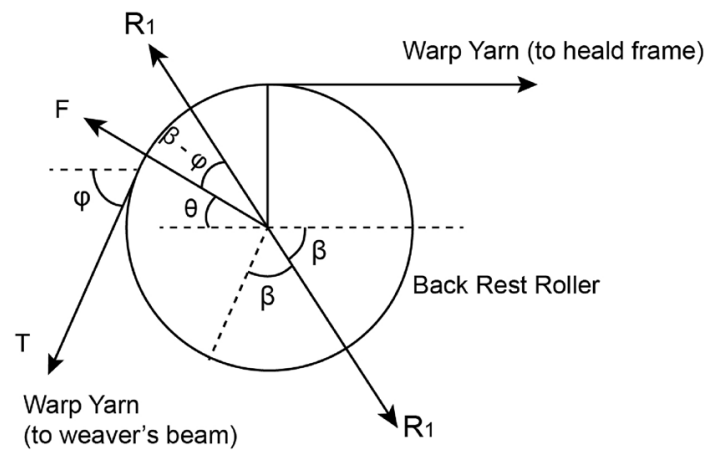

Fig. 8 Warp tension due to back rest and yarn path
Experimental results are used to plot 3 graphs (Fig. 11) for changes in shed angles depending on weft yarn count and composition. Figure 11 shows that curves for coarser yarns at higher shed angles $\left(30^{\circ}\right)$ will increase the pick spacing from ref. pick spacing at pick sequence 0 hence will increase starting mark intensity.

\subsection{Effect of automatic start offset, stop position and take-up correction on starting mark correction}

Picanol looms have internal built-in settings for starting mark correction. These settings are: Automatic Start Offset (ASO), pick stop position of loom and take-up correction (TUCO) or correction control take-up motion by electronic take-up motor. ASO means the amount of times loom must pass through beat-up $\left(0^{\circ}\right)$ position before starting the pick insertion. As shed angle may enhance the starting 


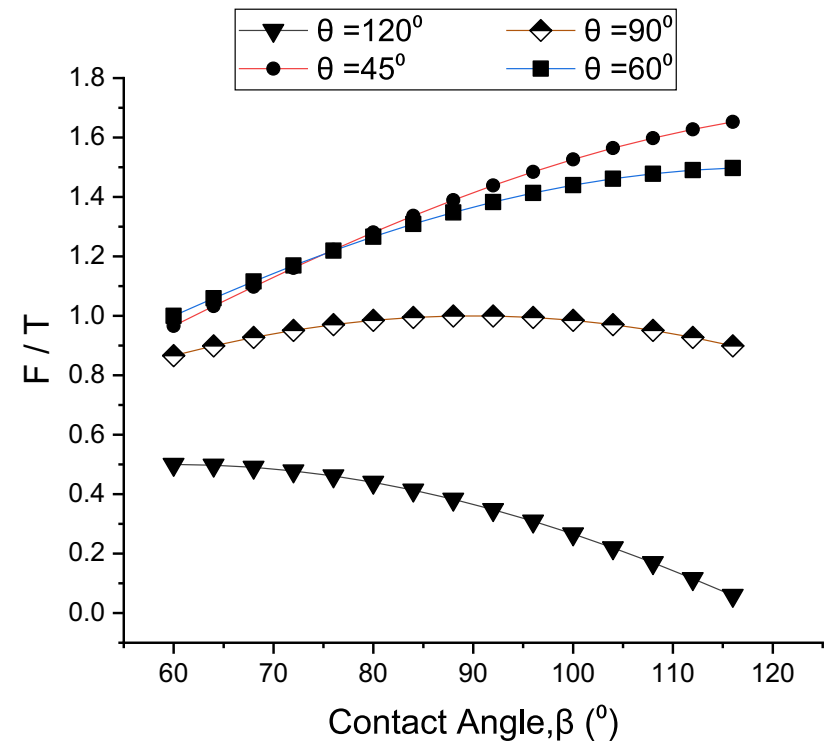

Fig. 9 Pick spacing $(\mu \mathrm{m})$ for different back-rest height against specific shed angle

mark intensity and fabric properties, calibration in these settings may be reflected in the starting mark. All samples having stating mark with variable pick spacing of different weft were used, and with changed value of ASO and stop position the obtained fabric was checked and avg. pick spacing was also measured and their standard deviations, $\mathrm{CV} \%$ are listed in Table 10 . For starting mark generation, loom was stopped for $2 \mathrm{~min}$.

Experimental results show that for dense mark (higher pick density) with an increase in ASO value, the pick density will reduce and for open mark with a decrease in ASO value, pick density will increase. Both will reduce the starting mark intensity.

The TUCO 1 option adjusts the pick density during loom braking [39]. TUCO 2 adjusts the pick density during loom restart. If a loom stop occurs within the first 10 picks, no
TUCO procedure is performed. Considering the standard pick density as $100 \%$, due to variations in pick spacing this value has to be increased for higher pick density and vice versa. TUCO 3 and 4 have negative and positive value, where positive value will increase the pick density and negative mark will decrease it. Table 11 shows the experimental results for the obtained data.

From Table 11, it is clear that TUCO can be essential for starting mark solving, but the variations observed were too much to accept. As a result, effective customization is a matter here to consider.

\subsection{Effect of take-up and let-off disturbance on fabric causing starting mark}

According to Eq. (4), balanced weaving condition produces a uniform pick density in the fabric [33]. The disturbances making variations in pick density mainly come from the take-up of fabric and let-off of warp ends from weaver's beam. In weaving, one of these two disturbances may happen or both may take place at a time. According to Chen [33], the disturbance to balanced weaving is only from the take-up motion and the expression for pick spacing then reduces to

$\mathrm{d} P=\cos \varphi d \Delta I-(I+\Delta l) \sin \varphi \mathrm{d} \varphi$

where $\mathrm{d} P=$ changes in take-up length, $\mathrm{d} \Delta /=$ changes in $\Delta l$. Equation (6) indicates that a disturbance in the takeup $\mathrm{d} P$ will cause $\Delta /$ and $\varphi$ to change. If the disturbance is caused by taking up more fabric length than required, $\mathrm{d} P$ is positive; otherwise, it is negative. According to Eq. (6), an increase in $\mathrm{d} P$ will also cause an increase in $\Delta l$, i.e., a positive $\mathrm{d} \Delta l$, and a decrease in $\mathrm{d} \varphi$ and vice versa. When the take-up motion takes up more fabrics than required, a positive $d P$ will generate. The immediate effect of this disturbance on the pick density is that the on-loom weft density is reduced from its normal value to a certain level.

Table 8 Beat-up force required for pick spacing and warp tension variation

\begin{tabular}{llllllcccc}
\hline Sample & $\begin{array}{l}\text { Changes in yarn } \\
\text { tension, } \mathrm{CN}\end{array}$ & $\begin{array}{l}\text { Fabric ten- } \\
\text { sion, cN }\end{array}$ & $\begin{array}{l}\text { Cloth-fell dis- } \\
\text { tance, } \mathrm{L} \text { (in.) }\end{array}$ & $\begin{array}{l}\text { Ref. pick spac- } \\
\text { ing, S } \mu \mathrm{m}\end{array}$ & $\begin{array}{l}\text { Starting mark pick } \\
\text { spacing, } \mu \mathrm{m}\end{array}$ & $\begin{array}{l}Z, \mu \mathrm{m} \\
E_{1} / L_{1}\end{array}$ & $E_{2} / L_{2}$ & $\mathrm{Rb}, \mathrm{N}$ \\
\hline SMP-01 & 96.8 & 97.2 & 0.1 & 488.5 & 550 & 61.5 & 39.9 & 40.2 & 6.5 \\
SMP-02 & 86.8 & 87 & 0.109 & 461.8 & 482 & 20.2 & 109.2 & 109.5 & 19.9 \\
SMP-03 & 76.8 & 77 & 0.108 & 437.9 & 470 & 32.1 & 60.83 & 60.98 & 11.06 \\
SMP-04 & 79.3 & 80.4 & 0.107 & 488.5 & 551 & 62.5 & 32.21 & 32.7 & 5.7 \\
SMP-05 & 69.3 & 70.1 & 0.106 & 461.8 & 488 & 26.2 & 67.23 & 68.01 & 11.88 \\
SMP-06 & 59.3 & 60 & 0.105 & 437.9 & 499 & 61.1 & 24.66 & 24.96 & 4.35 \\
SMP-07 & 49.4 & 50.5 & 0.104 & 488.5 & 571 & 82.5 & 15.20 & 15.54 & 2.61 \\
SMP-08 & 39.4 & 40 & 0.103 & 461.8 & 500 & 38.2 & 26.2 & 26.61 & 4.5 \\
SMP-09 & 29.4 & 30.2 & 0.102 & 437.9 & 529 & 91.1 & 8.2 & 8.42 & 1.41 \\
\hline
\end{tabular}




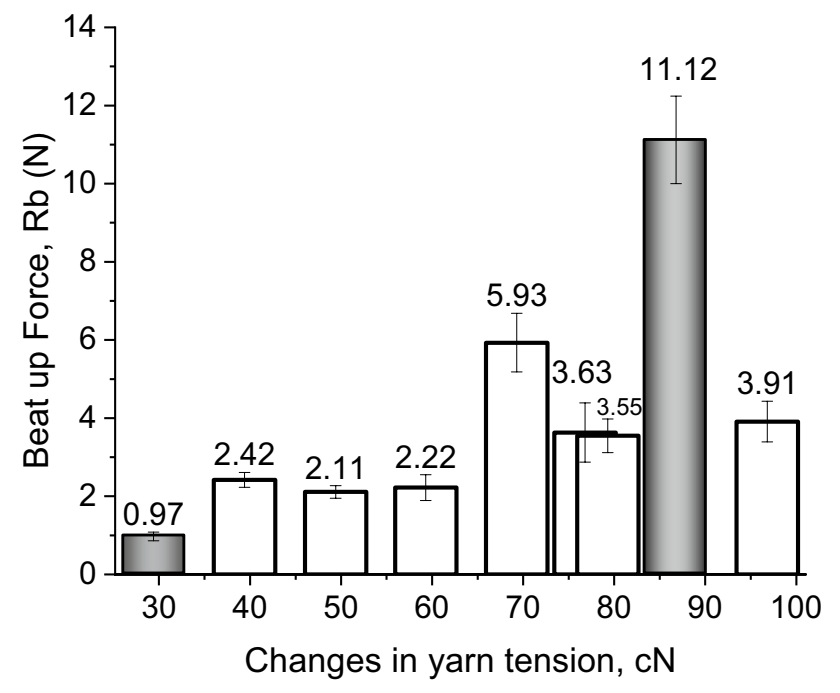

Fig. 10 Beat-up force $(\mathrm{N})$ required for changes in yarn tension against specific shed angle

This disturbance will increase the warp tension, leading to stretched warp ends, with a positive $\mathrm{d} \Delta l$, and a negative $\mathrm{d} \varphi$. When the fabric is withdrawn from the loom and relaxed, the warp extension $\Delta /$ will recover, causing to a higher pick density [33]. Since the weaving angle was smaller in the on-loom fabric, during crimp interchange in a relaxed fabric, the weaving angle in the warp direction will definitely increase. Due to let-off disturbance, there is no change in the take-up length of the fabric, i.e., $\mathrm{d} P=0$. So, we get,

$\mathrm{d} l=P \frac{\tan \varphi}{\cos \varphi} \mathrm{d} \varphi-\mathrm{d} \Delta l$ where, an increase in $d /$ leads to a positive $d \varphi$, a decreased extension, as well as a negative $\mathrm{d} \Delta /$ and vice versa. When balanced weaving is disturbed by let-off, the warp tension will decrease and the cloth fell will move forward due to tension balance between the warp and fabric, resulting in a lower pick density [33]. This disturbance will lead to a higher $\varphi$, and the fabric will have a higher warp crimp.

\section{Conclusion}

The possibilities of attuning shed geometry have been explored here to prevent starting marks by using results from the analyses and experiments referred to previous works. Whether open or dense marks are generated, depends to a greater extent on the performance level of the warp tensioning device used. This experiment highlights, for weaving with core-spun weft yarn, with shed angle of $26^{\circ}$, and an increase in heald frame height will tend to dense mark as well as higher coefficient of variation (CV \% = 1.77). When weaving $100 \%$ cotton fabric, with shed angle of $28^{\circ}$, an increase in back-rest roller height will decrease the starting mark visibility and also reduce the variation. Higher shed angle for polyester weft yarn sample will reduce the coefficient of variation (CV \% $=0.7$ ) of its pick density. The visibility of starting mark will reduce with an increase in warp tension for low beat-up force. For coarser yarns at higher shed angles $\left(30^{\circ}\right)$, starting mark intensity will increase (CV \% $=2.17$ ). Higher pick density with an increase in ASO value will reduce the pick density. This work paves the way for prognosticating the possibility of breakage rate of yarns and loom setting before weaving.

Table 9 Pick spacing observation for various weft composition and count

\begin{tabular}{|c|c|c|c|c|c|c|c|c|}
\hline Sample & Weft composition & Shed angle & Weft count & Loom stoppage & ppcm & Avg. pick spacing & SD & CV \% \\
\hline SMP-01 & \multirow[t]{3}{*}{ Polyester } & $30^{\circ}$ & 34 Tex & $2 \min$ & \multirow[t]{3}{*}{20} & 501.5294 & \multirow[t]{3}{*}{5.98} & \multirow[t]{3}{*}{$1.20 \%$} \\
\hline SMP-04 & & $28^{\circ}$ & 50 Tex & $2 \min$ & & 492.7412 & & \\
\hline SMP-07 & & $26^{\circ}$ & 67 Tex & $2 \min$ & & 490.1176 & & \\
\hline SMP-02 & \multirow{3}{*}{$\begin{array}{l}\text { Core-spun yarn (Cot- } \\
\text { ton- spandex) }\end{array}$} & $30^{\circ}$ & 52 Tex & $2 \min$ & \multirow[t]{3}{*}{22} & 475.7471 & \multirow[t]{3}{*}{5.39} & \multirow[t]{3}{*}{$1.15 \%$} \\
\hline SMP-05 & & $28^{\circ}$ & 40 Tex & $2 \min$ & & 471.0588 & & \\
\hline SMP-08 & & $26^{\circ}$ & 32 Tex & $2 \min$ & & 464.9882 & & \\
\hline SMP-03 & \multirow[t]{3}{*}{ Cotton } & $30^{\circ}$ & 50 Tex OE & $2 \min$ & \multirow[t]{3}{*}{23} & 447.6647 & \multirow[t]{3}{*}{4.39} & \multirow[t]{3}{*}{$0.991 \%$} \\
\hline SMP-06 & & $28^{\circ}$ & 37 Tex OE & $2 \min$ & & 443 & & \\
\hline SMP-09 & & $26^{\circ}$ & 30 Tex OE & $2 \min$ & & 438.8824 & & \\
\hline
\end{tabular}




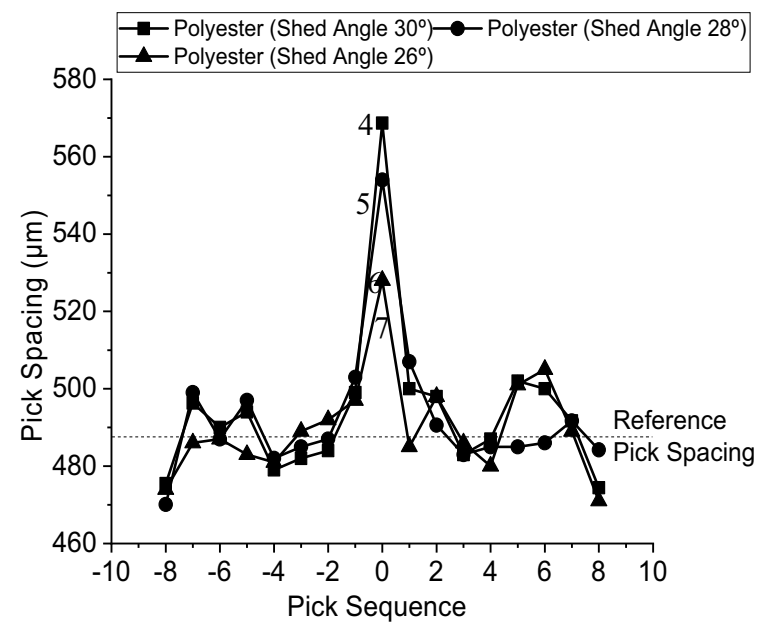

(a)

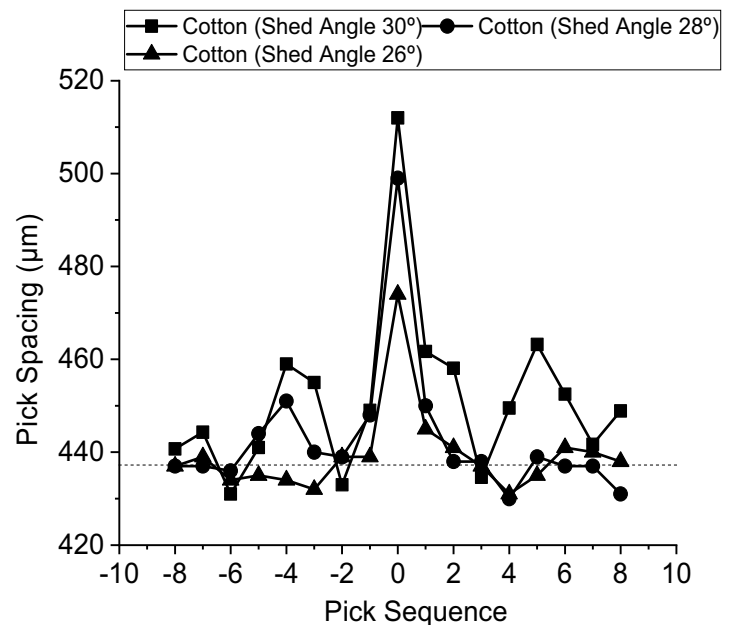

(b)

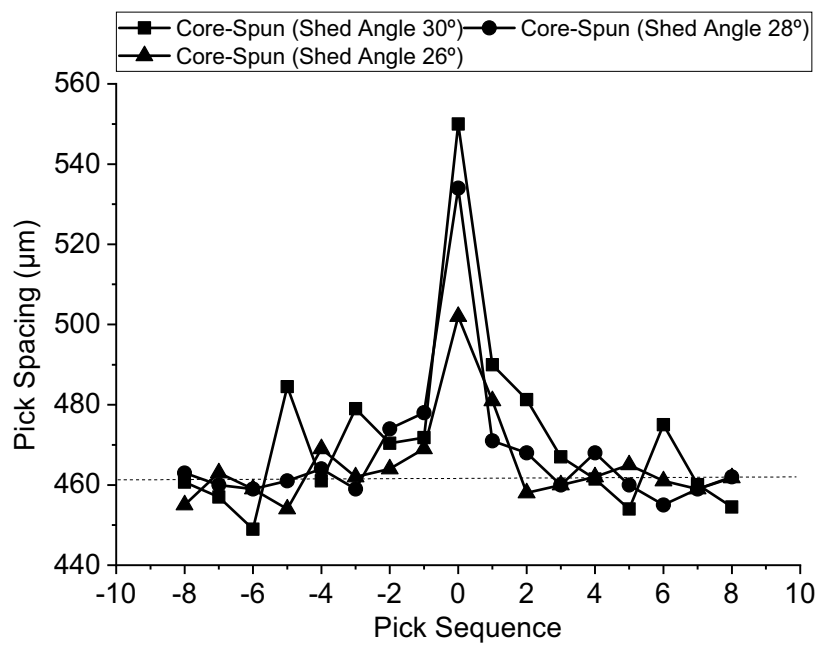

(c)

Fig. 11 Pick Spacing $(\mu \mathrm{m})$ for weft yarn count and composition at different shed angle $\left(28^{\circ}, 26^{\circ}, 28^{\circ}\right)$. a Polyester weft; $\mathbf{b}$ cotton weft; c corespun weft

Table 10 Pick spacing observation for various weft composition and count

\begin{tabular}{|c|c|c|c|c|c|c|c|c|c|}
\hline Sample code & Shed angle & $\begin{array}{l}\text { Pick spacing, } \\
\mu \mathrm{m} \text { (before) }\end{array}$ & $\begin{array}{l}\text { Initial ASO } \\
\text { value }\end{array}$ & $\begin{array}{l}\text { Changed } \\
\text { ASO value }\end{array}$ & $\begin{array}{l}\text { Initial stop } \\
\text { position }\end{array}$ & $\begin{array}{l}\text { Changed stop } \\
\text { position }\end{array}$ & $\begin{array}{l}\text { Pick spac- } \\
\text { ing, } \mu \mathrm{m} \\
\text { (after) }\end{array}$ & SD & CV \% \\
\hline SMP-01 & $30^{\circ}$ & 550 & 1 & -1 & $260^{\circ}$ & $290^{\circ}$ & 495 & 10.7 & 2.17 \\
\hline SMP-04 & & 446 & 2 & 3 & $260^{\circ}$ & $245^{\circ}$ & 481 & & \\
\hline SMP-07 & & 571 & 1 & -2 & $265^{\circ}$ & $290^{\circ}$ & 502 & & \\
\hline SMP-02 & $26^{\circ}$ & 482 & 0 & -2 & $270^{\circ}$ & $290^{\circ}$ & 460 & 4.04 & 0.87 \\
\hline SMP-05 & & 502 & 0 & -2 & $270^{\circ}$ & $290^{\circ}$ & 468 & & \\
\hline SMP-08 & & 441 & 1 & -2 & $260^{\circ}$ & $240^{\circ}$ & 465 & & \\
\hline SMP-03 & $28^{\circ}$ & 410 & 1 & 2 & $270^{\circ}$ & $260^{\circ}$ & 439 & 7.5 & 1.68 \\
\hline SMP-06 & & 499 & -1 & -3 & $260^{\circ}$ & $290^{\circ}$ & 447 & & \\
\hline SMP-09 & & 529 & 2 & -1 & $250^{\circ}$ & $270^{\circ}$ & 454 & & \\
\hline
\end{tabular}


Table 11 Pick spacing observation for different take-up correction (TUCO)

\begin{tabular}{|c|c|c|c|c|c|c|c|c|c|}
\hline Sample Code & Shed angle & $\begin{array}{l}\text { Pick spacing } \\
\text { (before) }\end{array}$ & TUCO 1 (\%) & TUCO 2 (\%) & TUCO 3 & TUCO 4 & $\begin{array}{l}\text { Pick spacing } \\
\text { (after) }\end{array}$ & SD & CV \% \\
\hline SMP-01 & $30^{\circ}$ & 550 & 90 & 90 & -1 & -1 & 491 & 13.87 & 2.85 \\
\hline SMP-04 & & 446 & 120 & 110 & 3 & 2 & 499 & & \\
\hline SMP-07 & & 571 & 80 & 90 & -3 & -2 & 472 & & \\
\hline SMP-02 & $26^{\circ}$ & 482 & 90 & 90 & -1 & -1 & 462 & 14 & 3.09 \\
\hline SMP-05 & & 502 & 80 & 90 & -2 & -2 & 436 & & \\
\hline SMP-08 & & 441 & 110 & 110 & -1 & -1 & 458 & & \\
\hline SMP-03 & $28^{\circ}$ & 410 & 120 & 120 & 2 & 2 & 440 & 12.5 & 2.90 \\
\hline SMP-06 & & 499 & 80 & 90 & -2 & -1 & 434 & & \\
\hline SMP-09 & & 529 & 70 & 80 & -3 & -2 & 416 & & \\
\hline
\end{tabular}

Acknowledgements The authors would like to express thank and gratitude toward Sister Denim Composite Limited (Thermax Group), Narsingdi, Bangladesh, for providing machineries and equipment on time during the course of this research work and the Bangladesh University of Textiles, Dhaka and National Institute of Textile Engineering \& Research, Savar, Dhaka for other assistance that made this work possible. The authors declare that they have no conflict of interest.

\section{Compliance with ethical standards}

Conflict of interest The authors declare that they have no competing interests.

\section{References}

1. Islam SA (2001) Features identification of set marks in weaving. Can Text J 118(4):28-31

2. Greenwood K, Cowhig WJ (1956) 16-The position of the cloth fell in power looms: Part I-Stable weaving conditions. J Text Inst Trans 47(5):T241-T254

3. Greenwood K, Cowhig WJ (1956) 17-The position of the cloth fell in power looms: Part II-Disturbed weaving conditions. J Text Inst Trans 7(5):T255-T273

4. Greenwood K, Vaughan GJ (1956) The position of the cloth fell in power looms: Part III. Experimental. J Text Inst Trans 47(5):T274-T286

5. Yee Lan T (1997) A study of start-up marks of woven fabrics. Res J Text Apparel 1(1):71-83

6. Islam A, Bandara M (1996) Yarn spacing measurement in woven fabrics with specific reference to start-up marks. J Text Inst 87(1):107-119

7. Ghosh SK, Sen MMK, Bairagi MS, Bhattacharyya MR (2016) Causes of starting mark on silk fabric and its remedies. Am Int J Res Sci Technol Eng Math (AIJRSTEM) 16(1):79-83

8. Kumpikaite E, Milašius VJMS (2003) Analysis of interrelation between fabric structure factors and beat-up parameters 9(2):228-232

9. Luciano Corain SR, Marco Novella (1995) Device for automatically varying the position of the shed vertex in a loom. United States Patent US08,136,450

10. Dornier $P$ (1992) Loom arrangement for fabrics sensitive to weaving stop marks. United States Patent 5,082,029
11. Klaus Meroth DW-K (1989) Method and system for starting a power loom. United States Patent 4,837,485,

12. Benelli DD (1992) Prevention of weft streaks after loom start up. United States Patent 5,090,452

13. Picanol (1993) Starting Marks. Technical Publication, vol R136. Picanol, Belgium

14. Shuichiro Imamura AA (1984) Weft-bar (set mark) prevention system for a loom. United States Patent 4,480,665,

15. Islam A, Solutions TB (1998) Prevention of set marks in weaving. $J$ Inst Text Eng Technol ITET 8:42-47

16. Baldassarre A, De Lucia M, Nesi P, Rossi F, Zamberlan J (1999) Real-time defect detection on cloths. In: Optical measurement systems for industrial inspection. International Society for Optics and Photonics, pp 353-365

17. Chen G, Wang Y (2007) A low-tension method for start-up mark prevention in weaving. J Text Inst 98(1):81-85

18. Neogi SK (2016) Role of yarn tension in weaving. WPI Publishing, New Delhi

19. Sheikhzadeh M, Hosseini S, Darvishzadeh M (2007) Theoretical evaluation of warp tension variations during weaving process. Indian J Fibre Text Res 32:377-380

20. Turhan Y, Tokat S, Eren R (2007) Statistical and computational intelligence tools for the analyses of warp tension in different back-rest oscillations. Inf Sci 177(23):5237-5252

21. Nilakantan G, Gillespie JW Jr (2013) Yarn pull-out behavior of plain woven Kevlar fabrics: Effect of yarn sizing, pullout rate, and fabric pre-tension. J Compos Struct 101:215-224

22. Bai R, Li W, Lei Z, Ma Y, Qin F, Fang Q, Chen X, Chen T (2018) Experimental study of yarn friction slip and fabric shear deformation in yarn pull-out test. Compos A Appl Sci Manuf 107:529-535

23. Weise $D$, Vorhof $M$, Brünler R, Sennewald C, Hoffmann G, Cherif $C$ (2018) Reduction of weaving process-induced warp yarn damage and crimp of leno scrims based on coarse high-performance fibers. 0040517518809049

24. Saiman $M$, Wahab M, Wahit $M$ (2014) The effect of fabric weave on the tensile strength of woven kenaf reinforced unsaturated polyester composite. In: Proceedings of the international colloquium in textile engineering, fashion, apparel and design 2014 (ICTEFAD 2014), 2014. Springer, New York, pp 25-29

25. Grujicic M, Yavari R, Snipes J, Ramaswami S, Yen C-F, Cheeseman BA (2014) The effect of plain-weaving on the mechanical properties of warp and weft $\mathrm{p}$-phenylene terephthalamide (PPTA) fibers/yarns. J Mater Sci 49(24):8272-8293

26. Gu H (1984) Reduction of warp tension fluctuation and beatup strip width in weaving. Text Res J 54(3):143-148 
27. Gloy Y-S, Sandjaja F, Sandjaja F, Gries T (2015) Model based self-optimization of the weaving process. CIRP J Manuf Sci Technol 9:88-96

28. Çelik Ö, Recep E (2014) Mathematical analysis of warp elongation in weaving machines with positive backrest system. TEKSTIL ve KONFEKSIYON 24(1):56-65

29. Genbhardt P, Weissenberger W (1987) Essential aspects of processing filament yarns on air-jet weaving machines. Text Prax Int 1340-1343

30. Katunskis J (2004) Theoretical and experimental beat-up investigation. Theor Exp Investig 12(3):24-28

31. Janicijevic D, Louven J, Ortmann H, Motz K, Laukamp T, Langer $M$, Mueller $H$ (2015) Weaving machine having movable shed opening limiter device. U.S. Patent No. 8,939,179

32. Catling $\mathrm{H}$ (1958) 17-Some effects of sinusoidal periodic yarn thickness variations on the appearance of woven cloth. J Text Inst 49(5):T232-T246

33. Chen $X$ (2005) Characteristics of cloth formation in weaving and their influence on fabric parameters. Text Res J 75(4):281-287
34. Patil MTC, Kadam MJ, Patil MY (2016) Air jet weaving: control of weft breakages for cotton \& polyester weft yarn. Int J Text Eng Process 2:1-6

35. Turhan Y, Eren R (2012) The effect of loom settings on weavability limits on air-jet weaving machines. J Text Res 82(2):172-182

36. House D, Breen D (2000) Cloth modeling and animation. AK Peters/CRC Press, London

37. Stemheim A, Grosberg PJ (1991) Weaving with constant beat-up force. J Text Inst 82(3):317-323

38. Jadhav $P$, Dhole $P$, Turukmane $R$ (2018) Investigation an impact of weft count and pick densities on allied fabric properties. Int J Text Eng Process 4:14-17

39. Picanol (2014) Original setting manual. Technical Publication, Picanol, Belgium

Publisher's Note Springer Nature remains neutral with regard to jurisdictional claims in published maps and institutional affiliations. 